\title{
Pensions crisis: the government must act
}

\author{
Fiona Godlee editor in chief
}

The BMJ

It would be a tragic irony if something as fundamentally benign and beneficial as doctors' pensions proved to be the final downfall of the NHS. But when senior doctors find themselves with little choice but to reduce sessions, stop doing overtime, or retire early because of changes to the way their pensions are taxed, this may be our new reality.

How has it come to this? As articles this week explain, the seeds were sown with the move away from a final salary scheme to one with defined benefits, coupled with successive reductions in the annual tax-free allowance. But the killer blow has been the introduction in 2016 of the tapered annual allowance, whereby the more someone earns over a certain amount the less their annual allowance is. Added to this, all income is now counted, including overtime and pension growth. As Paul Youngs puts it, "This creates a spiral of taxation: the more our pensions grow, the less they are allowed to grow without being hit by additional tax" (doi:10.1136/bmj.15195).

The government seems at last to be listening and has scrapped its initial consultation on offering limited flexibility. It is now considering "full flexibility"-allowing employees to take a proportion of their employers' contribution as salary rather than through pension payments-and a review of the tapered annual allowance. This is a well earned victory for the BMA but provides only short term relief, says its chair, Chaand Nagpaul (doi:10.1136/bmj.15135). He advocates wider reform of the annual allowance.

To readers still struggling to understand the issues I recommend the editorial by Antony Goldstone and David Bailey (doi:10. 1136/bmj.14952). The tapered allowance is, they say, poorly designed. But even the annual allowance makes little sense in a defined benefit scheme, when tax relief is adequately limited by the lifetime allowance. They call for the taper to be scrapped and for full flexibility to be given to all senior staff.

Could all of this upset, cost of locum cover, loss of expertise, and damage to patient care have been avoided? Goldstone and Bailey have seen no evidence that the government anticipated such catastrophic effects. But Youngs reports that the government's own impact statement predicted that people would respond by reducing their contributions and, once in the taper zone, reducing their income. If so, this was an entirely predictable and avoidable crisis.

Youngs quotes Adam Smith's The Wealth of Nations, which gives the four canons of taxation as equality, fairness, convenience, and efficiency. The current NHS pensions regime meets none of these ideals, he says. From what was once a simple system, with little need to engage with financial experts, we now have "tapering annual allowance, two pension schemes, and a myriad of financial complexity."

All our commentators agree that change cannot wait for the next tax year. Some trusts have already felt the need to offer greater flexibility (doi:10.1136/bmj.15173), but this is no substitute for a national solution. The NHS workforce situation was already critical. It has now become acute, and the government must act swiftly to resolve matters. Rebuilding trust and restoring the workforce will be a much longer task. 